Published in final edited form as:

Int J Psychophysiol. 2010 August ; 77(2): 106-117. doi:10.1016/j.ijpsycho.2010.04.011.

\title{
Response to familiar faces, newly familiar faces, and novel faces as assessed by ERPs is intact in adults with autism spectrum disorders
}

\author{
Sara J. Webb ${ }^{1,2,4}$, Emily Jones ${ }^{1,2}$, Kristen Merkle ${ }^{8}$, Michael Murias ${ }^{1,2}$, Jessica Greenson ${ }^{2}$, \\ Todd Richards ${ }^{2,3}$, Elizabeth Aylward 2,5 , and Geraldine Dawson $2,4,6,7$ \\ 1 University of Washington Department of Psychiatry and Behavioral Sciences, Seattle, WA, USA \\ ${ }^{2}$ University of Washington Center on Human Development and Disability, Seattle, WA, USA \\ 3University of Washington Department of Radiology, Seattle, WA, USA \\ ${ }^{4}$ University of Washington Department of Psychology, Seattle, WA, USA \\ ${ }^{5}$ Seattle Children's Research Institute, Seattle, Washington, WA, USA \\ ${ }^{6}$ Autism Speaks, New York, USA \\ ${ }^{7}$ University of North Carolina Psychiatry Department, NC, USA \\ ${ }^{8}$ Vanderbilt University Institute on Imaging Sciences, Nashville, TN, USA
}

\begin{abstract}
Individuals with autism spectrum disorders (ASD) have pervasive impairments in social functioning, which may include problems with processing and remembering faces. In this study, we examined whether posterior ERP components associated with identity processing (P2, N250 and face-N400) and components associated with early-stage face processing (P1 and N170) are atypical in ASD. We collected ERP responses to a familiar repeated face (Familiar), an unfamiliar repeated face (Other) and novel faces (Novels) in 29 high functioning adults with ASD and matched controls. For both groups, the P2 and N250 were sensitive to repetition (Other vs. Novels) and personal familiarity (Familiar vs. Other), and the face-N400 was sensitive to repetition. Adults with ASD did not show significantly atypical processing of facial familiarity and repetition in an ERP paradigm, despite showing significantly poorer performance than controls on a behavioral test of face memory. This study found no evidence that early-stage facial identity processing is a primary contributor to the face recognition deficit in high functioning ASD.
\end{abstract}

\section{Keywords}

ERP; P100; N170; N250; autism; face memory

(C) 2010 Elsevier B.V. All rights reserved.

Contact: Box 357920, CHDD, Seattle WA 98195, 206-221-6461, sjwebb@u.washington.edu.

Publisher's Disclaimer: This is a PDF file of an unedited manuscript that has been accepted for publication. As a service to our customers we are providing this early version of the manuscript. The manuscript will undergo copyediting, typesetting, and review of the resulting proof before it is published in its final citable form. Please note that during the production process errors may be discovered which could affect the content, and all legal disclaimers that apply to the journal pertain. 


\section{Introduction}

Autism is defined by impairments in the areas of social interaction and communication and marked by the presence of a restricted repertoire of behavioral activities and interest. Although not identified as a core phenotype of autism spectrum disorders (ASD), face processing and recognition is thought to be a relative area of weakness for many individuals with ASD (for review see Dawson, Webb, McPartland, 2005; Jemel et al., 2006; Webb, 2008). Briefly, alterations in face processing in ASD may include: biases toward high spatial frequency information in faces (e.g., Deruelle et al., 2004; de Jong et al., 2008); reduced configural processing of faces (e.g., Faja et al., 2009; Teunisse and de Gelder, 2003); alternative patterns of attention to features within the face such as atypical or reduced eye attention (e.g., Langdell, 1978; Klin et al., 2002; Pelphrey et al., 2002; Sterling et al., 2008b); and differential patterns of responses to familiar vs. unfamiliar faces (Pierce et al., 2004; Pierce and Redcay, 2008). Although disruptions in the early processing of facial identity could contribute to face recognition deficits in ASD, few studies have examined this question. This paper uses electroencephalography (EEG) to explore the neural correlates of face identity processing in individuals with ASD relative to typical controls, in relation to behavioral measures of face memory, cognitive functioning, and symptom levels.

\section{Early Stage Processing of Faces}

Models of early-stage face processing have differentiated between face detection, involving the characterization of first-order facial structure, and face identification, which involves processing facial features and their second-order spatial relations (Bruce and Young, 1986; Maurer et al., 2002). One way to characterize these stages of face processing is to examine event-related potentials derived from electroencephalography, as specific waveform components have been associated with different stages of face processing.

Face detection has been associated with the N170, a posterior temporal component that peaks between 130 and $190 \mathrm{~ms}$ to face stimuli (Bentin et al., 1996). This component typically responds to faces on a categorical but not individual level or based on familiarity (e.g., Eimer, 2000; Herzmann et al., 2004; Tanaka et al., 2006; but see Caharel et al., 2005; Jemel et al., in press). Several studies have examined the N170 response to novel faces in individuals with ASD. Early work found that the N170 to faces was slowed in adolescents and adults with ASD (McPartland et al., 2004; O'Connor et al., 2007), suggesting differences in the structural phase of face processing that may be correlated with face recognition skills (McPartland et al., 2004). More recent work has suggested that latency differences are not observed when attention is directed to the eye region, although subtle atypicalities in holistic or configural processing (a reduced inversion effect) may remain (Webb et al., in press).

\section{Identity Processing}

Identity processing has been most consistently associated with the N250 and face-N400 components in typical adults. These components are negative going deflections over posteriortemporal electrodes measured between 200-300 ms and 300-500 ms after stimulus onset, respectively. Both components appear to be modulated by pre-experiment facial familiarity (Jemel et al., in press; Pickering et al., 2002; Schweinberger et al., 1995; Schweinberger et al., 2002b), face learning (Kaufmann et al., 2009; Tanaka et al., 2006), and face repetition (Begleiter et al., 1995; Eimer, 2000; Herzmann et al., 2004; Itier and Taylor, 2004; Schweinberger et al., 1995) suggesting that they are involved in processing facial identity. More recently, Jemel et al. (in press) found both the N170 and N250 amplitude signaled overt face recognition with later components such as the face-N400 increased in amplitude approaching overt recognition, suggesting that the face-N400 reflects the automatic activation of the face representation system without necessitating conscious recognition. 
Modulation of the $\mathrm{P} 2$ has also been associated with mnemonic processing of faces. The $\mathrm{P} 2$ is a positive component immediately following the N170 that is thought to reflect feedbackdriven reactivation of primary visual areas (Kotsoni et al., 2007). Modulation of the P2 has been found to be related to: feature detection and encoding (Itier and Taylor, 2002; Luck and Hillyard, 2004), perceptual expertise (Stahl et al., 2008; Wiese et al., 2008), short term memory (e.g., Taylor et al., 1990), subsequent recognition and recall (Garrett-Peters et al., 1994; Halit et al., 2000; Smith, 1993), pre-experimental familiarity (Caharel et al., 2002), and repetition (van Strien et al., 2009). It has been suggested that the P2 response to a face may reflect the degree to which continued configural processing is required for recognition (Caharel et al., 2002; Latinus and Taylor, 2006). The modulation of the P2, N250 and face-N400 by familiarity and repetition has not been examined in adults with ASD.

One previous study provides evidence that the neural correlates of identity processing may be atypical in young children with ASD. In a study with 3- to 4-year-old children, Dawson et al. (2002) found that children with ASD did not show differentiation between their mother's face and an unfamiliar face over components that responded to identity in typical children and children with developmental delay (the Nc, P400, and slow wave). Although the relation between these components and the adult $\mathrm{N} 250$ and face-N400 is unclear, these findings suggest that exploring the neural correlates of identity processing in adults with ASD is an important avenue of investigation.

\section{Current Paradigm}

In this report, we presented adults with ASD and IQ and gender matched controls three types of facial stimuli: a face that was a priori familiar (Familiar), a face that was repeated but initially unfamiliar (Other; Tanaka et al., 2006), and novel non-repeated faces (Novels). Familiarity was addressed by comparing the Familiar and Other stimuli, which differed on a priori exposure but were similar on within paradigm repetition. A picture of a personally familiar face was used because famous faces (often used with typical participants) may not have the same meaning to adults with ASD and familiar faces may evoke more typical neural activity in individuals with ASD (Pierce et al., 2004; Pierce and Redcay, 2008). Repetition was addressed by comparing the Other and Novels, which were both unfamiliar at the start of the paradigm but differed in repetition within the paradigm. High-density ERP responses were recorded and comparisons between face types were made at the P1, N170, P2, N250, and face$\mathrm{N} 400$. We also explored whether any variables that differed between the groups were related to symptom levels, language abilities, or behavioral measures of face recognition.

\section{Materials and Methods}

\section{Participants}

Two groups of adults participated in the study: 39 individuals with autism spectrum disorder (ASD) and 38 controls (neuropsychiatrically healthy individuals). ASD participants all had current clinical diagnoses of ASD and met research diagnostic standards for ASD based on the Autism Diagnostic Observation Schedule-Western Psychological Services (ADOS-WPS; Lord et al., 2002), Autism Diagnostic Interview social and communication domains (ADI-RWPS; Lord et al., 1994) and expert clinical diagnostic judgment based on DSM- IV criteria. Exclusionary criteria for participants with ASD included diagnosis of Fragile X, seizures, significant sensory or motor impairment, major physical abnormalities, serious head injury, and use of anti-convulsant or barbiturate medications. Exclusionary criteria for control participants included birth or developmental abnormalities, brain trauma, psychotropic medication usage, a first degree relative with autism, significant sensory or motor impairment, major physical abnormalities, or history of serious head injury. Some participants were involved in a larger study on face processing and social skills, results of which are reported 
elsewhere (Bernier et al., 2007; Faja et al., 2008; 2009; Kleinhans et al., 2009; Murias et al., 2007; Sterling et al., 2008a; 2008b; Webb et al., in press).

Twenty-nine individuals with ASD and 28 controls provided adequate artifact-free data. Of this ASD group, 12 participants met DSM-IV criteria for Autistic Disorder, 2 met criteria for Pervasive Developmental Disorder, Not Otherwise Specified, and 15 met criteria for Asperger's Disorder. Table 1 presents sample demographic and descriptive information, including Wechsler IQ scores (Wechsler, 1997) for both groups.

\section{Behavioral Tests}

The Wechsler Memory Scale - Third Edition, Faces Subtest (Wechsler, 1997) was used to assess immediate and delayed recognition memory for faces. Participants view 24 stimuli presented each for 2 seconds. To test recall, immediately and after a 30 minute delay, the participant is presented with 48 stimuli and the participant indicated if the stimulus was one that he or she was asked to remember.

\section{EEG Recording Procedure}

Stimuli and procedure-Stimuli consisted of gray-scale digital images of faces presented on a computer monitor with a grey background. All facial images were standardized so that the center of the eyes was presented at the center of the screen; visual angle for the faces was $11^{\circ}$ (height) by $7.6^{\circ}$ (width). Stimuli were presented randomly in 3 blocks of 58 trials. Trials came from four different stimulus categories: a repeating familiar face (Familiar, total trials $=$ 50 ), a repeating unfamiliar face (Other, total trials $=50$ ), non-repeating unfamiliar faces (Novels, total trials $=50$ ), and houses (Targets; total trials $=24$ ). The familiar face was a neutral picture of the participant's family member or close friend (e.g., parent, roommate, or spouse). The Other face was another participant's family member or close friend. The Familiar face and the Other face were matched on gender, ethnicity, age, similar hair styles, and general outline of the head; however, internal facial features (e.g., eye shade) differed. The Novel faces were 50 unique faces reflecting regional ethnic and racial demographics and were 50\% male, 50\% female.

To control for attention, participants were instructed to press a button to targets. Accuracy did not differ between groups; individuals with ASD $(M=433.1 \mathrm{~ms}, S D=66.9 \mathrm{~ms})$ were significantly quicker to identify targets than the control group $(M=479.6 \mathrm{~ms}, S D=94.7 \mathrm{~ms})$, $F(1,57)=4.8, p<.05$. This difference was primarily due to three outliers in the control group who had responses times $>2 \mathrm{SD}$ from the mean. When these outliers were removed, significant group differences were no longer observed $(F(1,52)=2.4, p=.13)$.

Data collection-EEG was recorded using a 128 channel Geodesic sensor net (Electrical Geodesics Incorporated; Eugene OR); impedances were kept below $40 \mathrm{k} \Omega$; amplification was set at 1000×; filtering was done through a $0.1 \mathrm{~Hz}$ high-pass filter and a $200 \mathrm{~Hz}$ elliptical lowpass filter; recording rate was $500 \mathrm{~Hz}$; and the vertex electrode was used as a recording reference. Trials consisting of a 500 millisecond baseline containing a visual fixation cross in the middle of the screen, 300 millisecond stimulus presentation, and inter trial interval, which varied randomly between 1000 and 1300 milliseconds.

Data editing and analysis-Trials were processed using Net Station 3.0 Waveform Tools (Electrical Geodesics, Eugene, OR). Post processing consisted of: (1) data were low-pass filtered at $30 \mathrm{~Hz}$; (2) channels were marked bad in each trial if the fast average amplitude exceeded $100 \mu \mathrm{V}$, differential average amplitude exceeded $50 \mu \mathrm{V}$, or the channel had zero variance; (3) electrodes for which more than $20 \%$ of trials were rejected by artifact were replaced using an algorithm that derived values from the neighboring sites by spline 
interpolation; (4) trials were marked bad if they contained more than 10 bad channels; (5) trials with eye movement artifacts were excluded; (6) data were averaged for each stimulus type and were re-referenced to an average reference. Peak values that could not be verified by visual inspection from leads that contributed to the P1 and N170 were removed from the analysis.

Electrodes of interest were selected based on review of the literature and examination of grand averages and individual participant data. Four regions of interest (ROIs) were selected (henceforth referred to as Webb ROIs): (a) posterior lateral left (leads 58, 59, 64, and 65), (b) posterior lateral right (leads 97, 92, 96, and 91), (c) posterior medial left (leads 66, 70, 71, and 72), (d) posterior medial right (leads 85, 90, 84, and 77). For the N170 (120 to $180 \mathrm{msec}$ after stimulus onset) and P1 (60 to $130 \mathrm{msec}$ ), the latency and amplitude of peaks occurring in the chosen time windows were extracted and visually verified by the authors (KM, SW). For the P2 (180 to $230 \mathrm{msec}$ ), N250a ( 200 to $250 \mathrm{~ms}$ ), N250b (250 to $300 \mathrm{msec}$ ), face-N400a (300 to $350 \mathrm{msec}$ ) and face- $\mathrm{N} 400 \mathrm{~b}$ ( 350 to $400 \mathrm{msec}$ ), the mean amplitude across a chosen time window was extracted. Amplitudes and latencies were averaged across the specified electrode regions for each participant. To compare our findings to previous reports of the N250, we examined two other topographical analyses: the averaged ROIs selected by Tanaka et al. (2006) (henceforth 'Tanaka ROIs': left ROI: 57, 58, 63, 64, 65, 69, 70; right ROI: 101, 97, 100, 96, 91, 95, 90); and individual electrodes corresponding to the 10-20 system (henceforth ' $10 / 20$ ROIs': T7/46, T8/109, P7/59, P8/92, TP9/57, TP10/101, P9/58, and P10/97) as utilized by Schweinberger et al. (2002a, 2002b) and Itier and Taylor (2004). See Figure 1.

For each component of interest, the Topography section reports main effects of region, hemisphere or group examined through a Diagnostic Group (ASD/Control) by Face Type (Familiar/Other/Novels), by electrode topography (Region by hemisphere for Webb ROIs; Hemisphere for Tanaka ROIs; or Hemisphere by Lead for 10/20 ROIs) repeated measures analysis of variance (RM ANOVA). Subsequently, the Familiarity Effects and Repetition Effects sections report effects involving Face Type examined through Diagnostic Group (ASD/ Control) by Face Type (For Familiarity effects: Familiar/Other; for Repetition effects, Other/ Novels), by electrode topography (Region by hemisphere for Webb ROIs; Hemisphere for Tanaka ROIs; or Hemisphere by Lead for 10/20 ROIs) RM ANOVAs. The Greenhouse-Geisser correction was employed and Fisher's Least Significant Differences was used for follow up tests in cases where interactions reached significance in the initial RM ANOVAs. Only effects that reached significance are reported in full. For analyses in which within-subject effects did not significantly interact with Diagnostic Group, this is stated in the text. Of note, this indicates that any effects of Region, Hemisphere and/or Face Type that were observed in those analyses did not significantly differ between the groups.

Of note, we also examined whether subtle group differences in the familiarity and repetition effects could have been masked by averaging across the electrodes included in the Webb ROIs by running a Face Type (Familiar vs. Other/Other vs. Novels) by Group RM ANOVA for P1 and N170 amplitude and latency, P2 mean amplitude, N250a and b mean amplitude, and faceN400a and b mean amplitude at each individual electrode included in the Webb ROIs; the pattern of findings did not reveal any additional group differences, and so are not further reported.

\section{Results \\ Behavioral results}

As we have previously reported, participants with ASD scored significantly lower on both the WMS Face Memory Subtest Immediate (WMS-Imm; ASD $M=7.6 S D 2.4$ ) and Delay (WMSDelay; ASD $M=7.9 S D$ 2.2) than Controls (WMS-Imm: $M=10.1 S D$ 2.3; WMS-Delay: $M=$ $9.4 S D$ 2.2); $F \mathrm{~s}(1,55)>6.2$, $p \mathrm{~s}<0.05$ (see Webb et al., in press). 


\section{ERP analyses}

P1 (Webb ROIs) Topography-P1 amplitude was more positive in the right versus left hemisphere $(F(1,53)=8.7, p<0.01)$, and at medial versus lateral leads $(F(1,53)=21.1, p<$ $0.01)$. These effects were qualified by a region by hemisphere interaction $(F(1,53)=4.7, p<$ $0.05)$, deriving from slightly more right-lateralized responses over lateral than medial regions (see Figure 2a/d). P1 latency did not differ by hemisphere or region ( $p s>0.05)$. These effects did not differ by group $(p s>0.05)$.

P1 (Webb ROls) Familiarity and Repetition effects-There were no significant effects of Face Type on P1 amplitude or latency ( $p s>0.05)$.

N170 (Webb ROls). Topography-N170 amplitude was more negative in the right than left $(F(1,54)=19.8, p<0.01)$, and at lateral versus medial leads, $(F(1,54)=10.3, p<0.01$; Figure 2). For N170 latency, there was a significant region by group interaction $(F(1,54)=$ $5.52, p<0.05$ ). Follow-up tests were inconclusive but suggested that the $\mathrm{N} 170$ peaked around $2 \mathrm{~ms}$ earlier laterally versus medially for the $\operatorname{ASD}$ group $(F(1,27)=3.5, p=0.07)$, but showed no regional variation in the control group $(F(1,27)<1.5, p>0.3)$.

N170 (Webb ROls) Familiarity effects-N170 amplitude was not modulated by Face Type, as seen in Figure 2. N170 mean latency was 2 ms faster to the Other than the Familiar $(F(1,54)=5.6, p<0.05)$; this did not differ by group $(p s>0.05)$.

N170 (Webb ROls) Repetition effects-N170 amplitude was not modulated by Face Type, as seen in Figure 2; N170 mean latency was $1.5 \mathrm{~ms}$ faster to the Other than the Novels $(F(1,54)=8.1, p<0.01)$; this did not differ by group $(p s>0.05)$.

P2 (Webb ROIs) Topography-P2 amplitude was more positive at medial versus lateral electrodes $(F(2,55)=5.9, p<0.01)$; this did not differ by group $(p \mathrm{~s}>0.05$; Figure 2$)$.

P2 (Webb ROIs) Familiarity effect-Average amplitude for Other was more positive than the Familiar, $F(1,55)=16.3, p<0.001$; Figure $3 \mathrm{a}$ ); this was qualified by an interaction between Face Type, Hemisphere, and Group $(F(1,55)=3.1, p<0.05)$ such that the Familiar vs. Other difference was found in both hemispheres for the Controls $(F \mathrm{~s}(1,27)>7.0, p \mathrm{~s}<0.05)$, but only in the right hemisphere for the ASD group (LH: $F(1,28)=1.9, p=0.18$; RH: $F(1,28)=8.6$, $p<0.01$; see Figure 4a).

P2 (Webb ROIs) Repetition effect-Average amplitude to Other was more positive than to Novels, $(F(1,55)=8.3, p<0.01$; Figure 3a). This was qualified by an interaction between Face Type, Hemisphere and Group $(F(1,55)=2.8, p<0.05$; Figure 5a) such that the Other vs. Novels difference was found over the left hemisphere for Controls (LH: $F(1,27)=6.1, p<$ 0.05 ; RH: $F(1,27)=2.8, p=0.11)$, but in the right hemisphere for the ASD group (RH: $F(1,28)$ $=8.4, p<0.01 ;$ LH: $F(1,28)=0.7, p=0.43)$.

N250 (Webb, Tanaka and 10/20 ROIs) Topography-The N250 from 200 to $250 \mathrm{msec}$ (N250a) and 250 to $300 \mathrm{msec}$ (N250b) average amplitude to all Face Types, regardless of ROI, was more negative-going for the ASD group than the control group $(F \mathrm{~s}(1,55)>4.6, p \mathrm{~s}<.05$; Figure $3 \mathrm{~b} / \mathrm{c})$. There were also main effects of region $(F \mathrm{~s}(1,54)>10, p<0.001)$ and electrode $(F \mathrm{~s}(3,54)>10, p<0.001)$ in the Webb and 10/20 ROI analyses respectively: N250a and b amplitude was more negative-going over posterior lateral than posterior medial regions, and more negative-going over temporal than posterior lateral electrodes (see Figure 2). This was qualified by a significant Lead by Group interaction over the 10/20 ROI for the N250b only $(F(3,165)=3.5, p<0.05)$; follow-up analyses confirmed that the more negative-going response 
for ASD versus controls was not apparent at T7/T8 $(p>0.1)$ but was apparent at all other sites $(p<0.05)$.

N250 (Webb, Tanaka and 10/20 ROIs) Familiarity effect-As seen in the grey shaded area in Figure 2 and the bar graphs in Figures $3 \mathrm{~b}$ and c, the average amplitude to the Familiar over N250a and N250b was more negative-going than the amplitude to the Other, regardless of ROI $(F \mathrm{~s}(1,55)>15.2, p s<0.001)$. These effects were qualified by a Face Type by Region effect in the Webb ROI analysis $(F \mathrm{~s}(1,54)>4, p<0.05)$, and a Face Type by Lead interaction in the 10/20 ROI analysis $(F \mathrm{~s}(1,162)>80, p<0.001)$, such that the Familiar vs. Other difference was larger over lateral posterior versus medial posterior ROIs, not apparent at T7/T8 ( $p>0.1)$, but was apparent at all other 10-20 electrode sites $(p s<0.05)$. Finally, there was a Group by Face Type by Hemisphere interaction in the Webb ROI analysis $(F \mathrm{~s}(1,54)>7, p<0.01)$; the Familiar vs. Other difference for both the N250a and b was present over both hemispheres for both groups ( $F s>5, p \mathrm{~s}<0.05$; Figures $4 \mathrm{~b}$ and $\mathrm{c}$ ) but was significantly right-lateralized in the ASD group $(F \mathrm{~s}(1,27)>7, p<0.01)$.

N250 (Webb, Tanaka and 10/20 ROls) Repetition effect-As seen in the grey shaded area in Figure 2 and the bar graphs in Figure $3 \mathrm{~b}$ and c, the average amplitude to the Novels was more negative-going than the amplitude to the Other across all ROIs (N250a: $F \mathrm{~s}(1,55)>$ $7.1, p \mathrm{~s}<0.01$; N250b: $F \mathrm{~s}(1,55)>34.1, p \mathrm{~s}<0.001)$; this effect did not differ by group ( $p \mathrm{~s}>$ $0.05)$. No other effects reached significance.

Face-N400 (Webb ROls). Topography-The face-N400 from 300 to $350 \mathrm{~ms}$ (face$\mathrm{N} 400 \mathrm{a}$ ) and 350 to $400 \mathrm{~ms}$ (face-N400b) was more negative-going in the lateral versus medial Webb ROIs $(F s(1,54)>8.0, p s<0.01)$; this topography did not differ by group (see Figure 2$)$. For the face-N400b only, amplitude was more negative-going over the left than right hemisphere $(F(1,54)=4.7, p<0.05)$. This was qualified by a Region by Hemisphere interaction, such that the lateralization of the face- $\mathrm{N} 400 \mathrm{~b}$ was more pronounced over lateral regions $(F(1,54)=5.2, p<0.05)$.

Face-N400 (Webb ROIs) Familiarity effect-Response to the Familiar and Other did not differ over either time window $(F s(1,57)<2.5, p s>0.1$; Figure 3$)$. There was a significant Face Type by Region interaction $(F s(1,54)>7.0, p s<0.01)$ : amplitude was more negativegoing over lateral vs. medial regions and this was more pronounced for Familiar than Other. There were also significant interactions between Face Type and Hemisphere for the faceN400b only $(F(1,54)=4.2, p<0.05)$, such that the response to Other was more negative-going over the left than the right hemisphere $(F(1,54)=14.2, p<0.001)$, but responses to familiar were bilateral $(F(1,54)=1.2, p=0.3)$. As well, there was a significant interaction between Face Type, Hemisphere and Group for the face-N400a only $(F(1,54)=5.5, p<0.05$; Figure 4d; Figure 4e shows the N400b for comparison): the Familiar and Other stimuli produced more differentiable responses over the right hemisphere than the left hemisphere for the ASD group $(F(1,54)=4.5, p<0.05)$ but not the Controls $(F(1,54)=2.7, p=0.1)$.

Face-N400 (Webb ROIs) Repetition effect-Response to the Novels was significantly more negative-going than response to the Other $(F s(1,55)>10$, ps $<0.001$; Figure $3 \mathrm{~d} / \mathrm{e})$. This was qualified by a Face Type by Hemisphere interaction $(F s(1,55)>4$, ps $<0.05)$; the Other vs. Novels difference was greater over the right than the left hemisphere (Figure $5 \mathrm{~d}$ ).

Correlations-We examined correlations between face memory (WMS-Imm and WMSDelay), language skills (verbal IQ) and symptom levels, with the mean amplitude of the N250 (Webb ROIs), and lateralization of the N250 and face-N400 familiarity effects (Familiar minus Other; Webb ROIs) and the P2 familiarity and repetition effects (Other minus Novels; Webb 
ROIs) in the ASD group only. These variables were selected because they differed between the groups. Of note, N250 and N400 amplitudes were averaged across a and b windows to reduce the number of comparisons.

As displayed in Figure 6a, more negative-going N250 amplitude (collapsed across lead groups) correlated with greater verbal IQ in all three conditions (Other, $r(29)=-0.41, p=0.01$; Novel, $r(29)=-0.43, p<0.05$; and Familiar faces, $r(28)=-0.43, p<0.05)$, and correlated with lower scores (fewer symptoms) on the social subdomain of the ADOS for the Familiar and Other categories only (Familiar: $r(28)=0.42, p<0.05$; Other: $r(29)=0.52, p<0.01$; Novel: $r$ (29) $=0.3, p=0.17$; Figure $6 \mathrm{~b}$ ); there were no significant correlations with the communication subdomain $(r s<0.1, p<0.6)$. As displayed in Figure $6 \mathrm{c}$, greater right-lateralization of the N250 familiarity effect (Familiar minus Other) correlated with lower ADOS total scores ( $r$ $(28)=0.43, p<0.05)$; this correlation was significant for the communication subdomain $(r$ $(28)=0.42, p<0.05)$ and marginally significant for the social subdomain $(r(28)=0.34, p=$ 0.08). Finally, as displayed in Figure 6d, greater right-lateralization of the P2 familiarity effect correlated with lower ADOS total scores $(r(28)=-0.40, p<0.05)$; this was marginally significant for the two subdomains (Social: $r(29)=-0.35, p=0.06$; Communication: $r(29)=$ $-0.32, p=0.1$ ). No significant correlations were found for the lateralization of the $\mathrm{P} 2$ repetition effect or the face-N400 familiarity effect.

\section{Discussion}

This study examined ERP responses to facial familiarity and repetition in individuals with ASD and matched controls. No group differences on early ERP correlates of attention and structural face processing (the P1 and N170; Figure 2) were found in this paradigm, suggesting that the $\mathrm{P} 1$ and N170 responses to upright faces in adults with ASD can resemble those seen in controls; this was also found with the same participants tested in a paradigm in which upright and inverted faces and houses were presented (Webb et al., in press). Further, both groups demonstrated modulation of posterior ERP components by pre-experimental familiarity and within-experiment repetition of facial stimuli, showing no evidence of atypicality in the neural correlates of identity processing in ASD. However, there were subtle differences in the P2 and $\mathrm{N} 250$ that suggest that identity processing may be achieved by the recruitment of additional compensatory processes or regions in the ASD group.

\section{N170 and P1 responses to faces}

Of note, two smaller previous studies (McPartland et al., 2004; O'Connor et al., 2007) have observed slower N170 responses to faces in individuals with ASD relative to control groups. Given that roughly double the number of participants were involved in the present study and Webb et al. (in press), the absence is unlikely to reflect a power issue. As discussed at length in Webb et al. (in press), procedural variations such as the use of a cross-hair to direct attention during recording, or the use of a low-working memory demand task administered during the ERP (a button press to each target, rather than a target count) could account for the more 'typical' P1 and N170 response. Heterogeneity across the ASD groups included in the studies is also likely important, as there is likely substantial variation in face processing abilities between individuals with ASD (for review see Jemel et al., 2006). Further work is required to delineate the circumstances under which individuals with ASD do and do not show atypicalities in the early neural correlates of face processing, which may provide increased insight into the nature and operation of these systems in ASD.

\section{Modulation of ERP components by familiarity}

The repeated familiar face (Familiar), in comparison to the repeated unfamiliar face (Other) was associated with ERP responses that were (1) less positive in amplitude at the P2 at right 
ROIs in the ASD group and bilaterally for the Control group; (2) more negative-going in amplitude at the N250; and (3) equivalent in amplitude for both groups at the face-N400. To better understand this pattern, we will first examine each component.

In the context of this experiment, a more positive $\mathrm{P} 2$ response was found to the Other than Familiar. This is consistent with the findings of Caharel et al. (2002), who also found a more positive $\mathrm{P} 2$ to an a priori unfamiliar repeated face than to an a priori familiar repeated face (the subject's face or a politician's face). Given that the Familiar stimulus was highly familiar and easily identified, greater $\mathrm{P} 2$ amplitude to the Other face may represent the process of continued configural processing for the purposes of identification (Caharel et al., 2002; Latinus and Taylor, 2006). Alternatively, the increased P2 amplitude to the Other face may reflect the greater disparity between feedback from currently stored representations and input processing in the case of the newly learned Other face relatively to the welllearned Familiar face (Kotsoni et al., 2007).

Similarly, a priori familiarity increased the negativity of the N250 in both groups, with the Familiar face producing more negative-going responses than the Other face. This is consistent with previous work with typical adults (e.g., Tanaka et al., 2006), wherein the response to the subject's own face was more negative-going than to the Other face (repeated unfamiliar face). Similarly, the N250 has been found to be more negative-going for familiar famous faces relative to unfamiliar faces (Begleiter et al., 1995; Pfutze et al., 2002; Schweinberger et al., 1995). Schweinberger et al. (2002b) localized the N250 to the anterior ventral temporal lobe, corresponding to the fusiform gyrus. Given Pierce and colleagues findings of normalized fusiform activation during perception of personally familiar individuals in ASD (Pierce et al., 2004; Pierce and Redcay, 2008), the apparently normal N250 response in individuals with ASD in this report may be the electrophysiological correlate of this activity.

The face-N400 did not differentiate between the Familiar or Other faces in either group. Although uniquely presented familiar faces typically elicit a more negative-going face-N400 than uniquely presented unfamiliar faces (Bentin and Deouell, 2000; Eimer, 2000; Jemel et al., 2005), evidence suggests this is not necessarily the case when faces are repeated. For example, Eimer (2000) observed that the difference in face-N400 response to pre-experimentally familiar (famous) and unfamiliar faces decreases with multiple repetitions (also see Barrett et al., 1988; Bentin and Deouell, 2000; Jemel, Calabria et al., 2003). Further, Paller et al. (2000) found that ERP responses to repeated named and unnamed faces did not differ across posterior regions around the face-N400 time window, and graphs presented by Caharel et al. (2002) indicate no differences in the posterior waveform in the face- $\mathrm{N} 400$ window between a repeated familiar face (self or politician) and a repeated unfamiliar face. Given the inclusion of the category of Novels in the present paradigm, it may also be that over the course of the 50 repetitions of Familiar and Other, any differences in a priori familiarity were reduced in comparison to the consistent uniqueness of the Novels.

Of note, familiarity did not modulate the amplitude of the P1 or N170 in the present study. This is consistent with the findings of a number of studies (e.g., Eimer, 2000; Herzmann et al., 2004; Tanaka et al., 2006). However, it is important to note that familiarity has been observed to affect the amplitude of the N170 under a range of experimental conditions, such as when a progression of decreasingly degraded famous faces are sequentially presented (Jemel et al., in press), when comparing own face or a politician's face to a repeated unfamiliar face (Caharel et al., 2002); or when making expression or identity judgments during the task (Caharel et al., 2005). Further, since only one face was used in the Familiar and Other conditions in the present study, low-level stimulus differences could have influenced the P1 and N170 responses and thus confounded any effects of personal familiarity. This limitation of the present paradigm could also account for the slightly shorter latency of the N170 to the Other face relative to the 
Familiar face. Using multiple stimuli per condition may be a more effective route to identifying effects of familiarity on the N170 response to faces; however, finding multiple individuals with which an individual with ASD is sufficiently familiar is a difficult task, and it may be impossible to match the level of familiarity across ASD and control groups.

In summary, both adults with ASD and typical controls registered information about the identity of a personally familiar face within $230 \mathrm{~ms}$ of stimulus presentation in the present paradigm, in accordance with evidence of apparently typical familiar face processing in ASD from fMRI (Pierce et al., 2004; Pierce and Redcay, 2008) and behavioral paradigms (Wilson et al., 2007).

\section{Modulation of ERP components by repetition}

While the Familiar and Other differed on a priori familiarity, the Other and Novels differed on repetition. The repeated unfamiliar face (Other), in comparison to the trial-unique unfamiliar faces (Novels) was associated with ERP responses that were (1) faster in latency at the N170 in both groups; (2) more positive in amplitude at the P2 over the left hemisphere for controls and the right hemisphere for the ASD group; (3) less negative-going in amplitude at the N250 for both groups; and (4) less negative-going in amplitude at the face-N400, with more pronounced effects over the right hemisphere for both groups.

Repetition decreased the latency of the response to the Other in comparison to the Novels (and the Familiar) at the N170. This latency "benefit" to the repeated unfamiliar face was, on average, very small with significant variability across subjects $(M=2 \mathrm{msec}, S D 7)$. Although the majority of reports have not observed differentiation over this component, two other reports have made similar observations (Itier and Taylor, 2004; Pfutze et al., 2002). Thus, it is possible that both familiarity and repetition subtly influence the speed at which the structural properties of a face can be processed and extracted in individuals with ASD as well as controls, although the disparities in the literature suggest this may be a task-dependent finding. It is also important to note that the greater perceptual variability included in the Novels category relative to the Other category could also have influenced the N170 component (Thierry, Martin, Downing and Pegna, 2007).

Repetition broadly increased the positivity of the $\mathrm{P} 2$, an effect also observed in typical controls by van Strien et al. (2009). The P2 may reflect re-activation of primary and secondary visual areas arising through visual cortical feedback (Kotsoni et al., 2006; Kotsoni et al., 2007), and effects of repetition may thus arise from feedback effects of stored partial face representations constructed for the Other face during the course of the experiment.

Repetition of the unfamiliar face also decreased the negativity of the N250; that is, the N250 response to the Other was less negative-going than the response to the Novels. This is consistent with the finding of decreased negativity of the N250 over multiple task-irrelevant repetitions of an unfamiliar face (Paller et al., 2000), and evidence from a recent MEG study that posterior temporal activity around 220 to $250 \mathrm{~ms}$ was reduced with repetition of unfamiliar neutral faces (Ishai et al., 2006). However, this is not consistent with reports that repetitions of the same face compared to novel faces have been found to generate a more negative-going N250, albeit greater for repetition of familiar than unfamiliar faces (e.g., Begleiter et al., 1995; Eimer, 2000; Herzmann et al., 2004; Itier and Taylor, 2004; Schweinberger et al., 1995, 2002b; 2005). Possibly, effects of repetition on the N250 are modulated by whether the mnemonic status of the face is a task-relevant dimension (as in Itier and Taylor, 2004; Schweinberger et al., 2002b). Indeed, in Tanaka et al. (2006), the Other face (a repeated familiarized non-target face) also did not generate a more negative-going N250 in comparison to a repeated familiarized target face (Joe/Jane; see also Trenner et al., 2004). 
Increased positivity of the $\mathrm{P} 2, \mathrm{~N} 250$ and face-N400 components was seen in both the control group and in individuals with ASD, who therefore showed evidence of apparently typical habituation of early neural responses to a repeated face, not significantly differing from controls in learning about the Other face. However, it is important to note that brain regions that are not well represented in ERP components (e.g., the amygdala) may not habituate at the same rate to facial stimuli in this group of individuals with ASD (Kleinhans et al., 2009).

\section{Evidence for compensatory recruitment in ASD?}

Whilst overall responses were very similar in the two groups, there were subtle differences in the magnitude and topography of responses that may suggest the rapid engagement of compensatory strategies for face processing in the ASD group. First, the mean amplitude of the N250 was more negative-going in all experimental conditions for the ASD group than the TYP group (Figure $3 \mathrm{~b}$ and c), and more negative-going amplitude correlated with better verbal skills in the ASD group (Figure 6c). Notably, typical adults who are trained to individuate faces from an unfamiliar category by associating each face with a letter show increases in the negativity of the N250 (Tanaka, 2009). It is possible that individuals with ASD with better language skills have a greater tendency to use language skills to scaffold face learning, resulting in recruitment of compensatory regions that contribute to identity processing. Indeed, examination of this relation in the control group revealed no significant relation between N250 amplitude and verbal IQ for any condition $(r \mathrm{~s}<0.2, p s>0.4)$. Presumably, typical adults would not need to scaffold face processing with verbal skill, relying on more face-specific mechanisms. Since other studies have also observed differential relations in ASD and control groups (e.g., McPartland et al., 2004; Webb et al. in press), contrasting ERP-behavior relations across a battery of tasks between ASD and control groups using statistical techniques such as structural equation modeling (e.g., Herzmann et al, 2010) may be an important avenue for future work.

Second, the effects of repetition (Other minus Novels) and familiarity (Familiar minus Other) on the P2 were only observed over the right hemisphere for the ASD group, whilst being bilateral (familiarity) or left-lateralized (repetition) in the controls (Figure 4a and Figure 5a). Notably, this indicates that the familiarity effect emerged later in the left-hemisphere for individuals with ASD (in the 200 to $250 \mathrm{~ms}$ window) relative to controls (the 180 to $230 \mathrm{~ms}$ window). Greater right-lateralization of the P2 familiarity effect was associated with fewer social and communication symptoms on the ADOS in the ASD group (Figure 6d). We also observed greater right-lateralization of the N250 familiarity effect (Familiar minus Other) in the ASD group (Figure $4 \mathrm{~b}$ and c); this lateralization was also associated with fewer social and communication symptoms (Figure 6c). Similarly, using fMRI, children and adults with ASD show right-lateralization of the familiarity effect in the fusiform gyrus (Pierce et al., 2004; Pierce and Redcay, 2008). Since the right hemisphere has been associated with holistic/ configural processing, individuals with better social and communication skills may be relatively more able to engage configural processes when viewing a highly familiar face than individuals with poorer social skills. Notably, more typical modulation of configural processing (measured with the N170 inversion effect) was related to higher social skills in this group of adults with ASD (Webb et al., in press). If these findings are replicable, it would suggest that adults with ASD could be trained to alter the early neural correlates of facial identity processing by learning to individuate faces and by learning to pay attention to configural information. We are currently exploring whether this is the case, and whether any resultant ERP changes would be associated with changes in performance on behavioral tests of memory.

\section{Relation between ERP and behavioral measures of face identity}

In the present study, the same group of individuals with ASD did not show significantly atypical neural correlates of facial identity, whilst displaying poor performance on several behavioral 
measures of face memory, and identity-related ERPs were not correlated with behavioral measures of face recognition performance. What can account for this apparent disparity? Possibly, task differences play a role - whilst a cross-hair directed attention to the eye region in the ERP paradigm, attention was self-directed in the behavioral test. Unusual processing styles may contribute to face recognition deficits in a less constrained context, such as atypical or reduced eye attention (e.g., Langdell, 1978; Klin et al., 2002; Pelphrey et al., 2002; Sterling et al., 2008b). Further, impairments in configural or holistic processing (e.g., Faja et al.,

2009; Teunisse and de Gelder, 2003) may contribute to poor behavioral face recognition, but may only be apparent in ERP measures when specifically examined, such as in a face inversion task (e.g., Webb et al., in press). Finally, the present ERP task may not have sufficiently taxed face learning or recognition: individuals were presented with only one familiar and one unfamiliar face, repeated 50 times (for a cumulative exposure time of 15 seconds), in contrast to the 24 faces presented only once for a 2 second duration in the WMS face memory scale. Notably, increased attention to internal versus external features facilitates unfamiliar face discrimination after 2 seconds but not 6 seconds of exposure for typical adults (Fletcher et al., 2008); the effects of subtle differences in processing style may have 'washed out' over the repeated stimulus presentations used in the present paradigm.

\section{Clinical Implications}

Although limited to adults with high-functioning ASD, the present study has potential clinical implications. The indication that atypicalities in the neural correlates of early-stage face processing assessed via ERPs are not a primary contributor to the face recognition deficit in high-functioning adults with ASD raises the possibility that more domain-general processes such as attention, memory span or encoding speed are the source of face recognition impairments in this group. Indeed, in the present group of adults with ASD there were also significant impairments in measures of house and object recognition memory, in addition to measures of face recognition (Webb et al., in press). Possibly, providing training on domaingeneral skills like attention may facilitate both face and object recognition for some individuals with ASD. The results also provide some suggestion that high-functioning adults with ASD may have developed compensatory strategies for face identity processing. Although the effects reported require replication before strong conclusions can be drawn, identifying the nature of these compensatory strategies may facilitate the development of face training programs for individuals with ASD. For example, if verbal skills enable adults with ASD to scaffold face learning, early intervention programs that significantly improve language development (e.g., Dawson et al., 2010) may have the additional benefit of improving facial identity processing.

\section{Conclusion}

Taken together, this pattern of results provides further evidence that early neural responses to faces measured over posterior regions can be apparently typical in individuals with ASD, when tested with simple paradigms (Webb et al., in press). Since behavioral measures revealed atypical face recognition in the ASD group, and there were no correlations between behavioral and ERP measures of face memory, the present study found no evidence that atypicalities in the neural correlates of early-stage face processing assessed via ERPs are a primary contributor to the face recognition deficit in ASD. Possibly, the WMS is difficult because individuals have to remember 24 faces that are presented once, whereas the ERP paradigm in the present study required individuals to remember one highly familiar face, and learn about one face that was repeated multiple times. Using an ERP paradigm with a greater memory load may reveal differences in the speed of face learning that could contribute to face recognition deficits on behavioral measures. Further work would be required to examine these possibilities. However, future conceptualizations of the "face processing" deficit in individuals with ASD may also 
need to take into consideration the potential that this system becomes more typical in high functioning adults.

\section{Acknowledgments}

This research was funded by a program project grant from the NIMH Studies to Advance Autism Research and Treatment (U54MH066399). The Murdock Trust provided funds for purchase of the system for recording electroencephalographic activity. We gratefully acknowledge the contributions of these funding sources, the Clinical and Statistical Cores of this project, and the individuals who participated in this study. Correspondence concerning this article should be addressed to Sara Jane Webb, Box 357920 CHDD 314C, University of Washington, Seattle, WA 98195, USA.sjwebb@u.washington.edu

\section{References}

Barrett SE, Rugg MD, Perrett DI. Event-related potentials and the matching of familiar and unfamiliar faces. Neuropsychologia 1988;26:105-117. [PubMed: 3362336]

Begleiter H, Porjesz B, Wang W. Event-related brain potentials differentiate priming and recognition to familiar and unfamiliar faces. Electroencephalogr. Clin. Neurophysiol 1995;94:41-49.

Bentin S, Allison T, Puce A, Perez E, McCarthy G. Electrophysiological studies of face perception in humans. J. Cogn. Neurosci 1996;8:551-565.

Bentin S, Deouell L. Structural encoding and identification in face processing: ERP evidence for separate mechanisms. Cogn. Neuropsychol 2000;17:35-54.

Bernier R, Dawson G, Webb S, Murias M. EEG mu rhythm and imitation impairments in individuals with autism spectrum disorder. Brain Cogn 2007;64:228-237. [PubMed: 17451856]

Bruce V, Young A. Understanding face recognition. Br. J. Psychol 1986;77:305-327. [PubMed: 3756376]

Caharel S, Courtay N, Bernard C, Lalonde R, Rebai M. Familiarity and emotional expression influence an early stage of face processing: An electrophysiological study. Brain Cogn 2005;59:96-100. [PubMed: 16019117]

Caharel S, Poiroux S, Bernard C, Thibaut F, Lalonde R, Rebai M. ERPs associated with familiarity and degree of familiarity during face recognition. Int. J. Neurosci 2002;112:1499-1512. [PubMed: 12652901]

Caldara R, Jermann F, Arango GL, Van der Linden M. Is the N400 category-specific? A face and language processing study. Neuroreport 2004;15:2589-2594. [PubMed: 15570158]

Chapman RM, McCrary JW, Chapman JA, Bragdon HR. Brain responses related to semantic meaning. Brain Lang 1978;5:195-205. [PubMed: 638735]

Dawson G, Carver L, Meltzoff AN, Panagiotides H, McPartland J, Webb SJ. Neural correlates of face and object recognition in young children with autism spectrum disorder, developmental delay, and typical development. Child Dev 2002;73:700-717. [PubMed: 12038546]

Dawson G, Webb S, McPartland J. Understanding the nature of face processing impairment in autism: Insights from behavioral and electrophysiological studies. Dev. Neuropsychol 2005;27:403-424. [PubMed: 15843104]

De Jong MC, van Engeland H, Kemner C. Attentional effects of gaze shifts are influenced by emotion and spatial frequency, but not in autism. J. Am. Acad. Child. Adolesc. Psychiatry 2008;47:443-454. [PubMed: 18356706]

Deruelle C, Rondan C, Gepner B, Tardif C. Spatial frequency and face processing in children with autism and asperger syndrome. J. Autism Dev. Disord 2004;34:199-210. [PubMed: 15162938]

Eimer M. Event-related brain potentials distinguish processing stages involved in face perception and recognition. Clin. Neurophysiol 2000;111:694-705. [PubMed: 10727921]

Faja S, Aylward E, Bernier R, Dawson G. Becoming a face expert: A computerized facetraining program for high-functioning individuals with autism spectrum disorders. Dev. Neuropsychol 2008;33:1-24. [PubMed: 18443967]

Faja S, Webb SJ, Merkle K, Aylward E, Dawson G. Brief report: Face configuration accuracy and processing speed among adults with high-functioning autism spectrum disorders. J. Autism Dev. Disord 2009;39:532-538. [PubMed: 18751880] 
Fletcher KI, Butavicius MA, Lee MD. Attention to internal face features in unfamiliar face matching. Br. J. Psychol 2008;99:379-394. [PubMed: 17706001]

Halit H, de Haan M, Johnson MH. Modulation of event-related potentials by prototypical and atypical faces. Neuroreport 2000;11:1871-1875. [PubMed: 10884035]

Herzmann G, Kunina O, Sommer W, Wilhelm O. Individual differences in face cognition: Brain-behavior relationships. J. Cogn. Neurosci 2010;22:571-589. [PubMed: 19400675]

Herzmann G, Schweinberger SR, Sommer W, Jentzsch I. What's special about personally familiar faces? A multimodal approach. Psychophysiology 2004;41:688-701. [PubMed: 15318875]

Horovitz SG, Rossion B, Skudlarski P, Gore JC. Parametric design and correlational analyses help integrating fMRI and electrophysiological data during face processing. Neuroimage 2004;22:15871595. [PubMed: 15275915]

Ishai A, Bikle PC, Ungerleider LG. Temporal dynamics of face repetition suppression. Brain Res. Bull 2006;70:289-295. [PubMed: 17027764]

Itier RJ, Taylor MJ. Inversion and contrast polarity reversal affect both encoding and recognition processes of unfamiliar faces: A repetition study using ERPs. Neuroimage 2002;15:353-372. [PubMed: 11798271]

Itier RJ, Taylor MJ. Effects of repetition and configural changes on the development of face recognition processes. Dev. Sci 2004;7:469-487. [PubMed: 15484595]

Jemel B, Mottron L, Dawson M. Impaired face processing in autism: Fact or artifact? J. Autism Dev. Disord 2006;36:91-106. [PubMed: 16477517]

Jemel B, Pisani M, Calabria M, Crommelinck M, Bruyer R. Is the N170 for faces cognitively penetrable? Evidence from repetition priming of Mooney faces of familiar and unfamiliar persons. Cogn. Brain Res 2003;17:431-446.

Jemel B, Pisani M, Rousselle L, Crommelinck M, Bruyer R. Exploring the functional architecture of person recognition system with event-related potentials in a within-and cross-domain selfpriming of faces. Neuropsychologia 2005;43:2024-2040. [PubMed: 16243050]

Jemel B, Schuller AM, Goffaux V. Characterizing the spatio-temporal dynamics of the neural events occurring prior to and up to overt recognition of famous faces. J. Cogn. Neurosci. in press doi: 10.1162/jocn.2009.21320.

Kaufmann JM, Schweinberger SR, Burton AM. N250 ERP correlates of the acquisition of face representations across different images. J. Cogn. Neurosci 2009;21:625-641. [PubMed: 18702593]

Kleinhans NM, Johnson LC, Richards R, Mahurin R, Greenson J, Dawson G, Aylward E. Reduced neural habituation in the amygdala and social impairments in autism spectrum disorders. Am. J. Psychiatry 2009;17:467-475. [PubMed: 19223437]

Klin A, Jones W, Schultz R, Volkmar F, Cohen D. Visual fixation patterns during viewing of naturalistic social situations as predictors of social competence in individuals with autism. Arch. Gen. Psychiatry 2002;59:809-816. [PubMed: 12215080]

Kotsoni E, Csibra G, Mareschal D, Johnson MH. Electrophysiological correlates of common-onset visual masking. Neuropsychologia 2007;45:2285-2293. [PubMed: 17452044]

Kotsoni E, Mareschal D, Csibra G, Johnson MH. Common-onset visual masking in infancy: Behavioral and electrophysiological evidence. J. Cogn. Neurosci 2006;18:966-973. [PubMed: 16839303]

Langdell T. Recognition of faces: An approach to the study of autism. J. Child Psychol. Psychiatry 1978;19:255-268. [PubMed: 681468]

Latinus M, Taylor MJ. Face processing stages: Impact of difficulty and the separation of effects. Brain Res 2006;1123:179-187. [PubMed: 17054923]

Lord, C. Autism diagnostic observation schedule: ADOS: Manual. Los Angeles, CAT: Western Psychological Services; 2002.

Lord C, Rutter M, Le Couteur A. Autism Diagnostic Interview-Revised: a revised version of a diagnostic interview for caregivers of individuals with possible pervasive developmental disorders. J. Autism Dev. Disord 1994;24:659-685. [PubMed: 7814313]

Luck SJ, Hillyard SA. Electrophysiological correlates of feature analysis during visual search. Psychophysiology 1994;31:291-308. [PubMed: 8008793] 
Maurer D, Le Grand R, Mondloch CJ. The many faces of configural processing. Trends Cogn. Sci 2002;6:255-260. [PubMed: 12039607]

McPartland J, Dawson G, Webb SJ, Panagiotides H, Carver LJ. Event-related brain potentials reveal anomalies in temporal processing of faces in autism spectrum disorder. J. Child Psychol. Psychiatry 2004;45:1235-1245. [PubMed: 15335344]

Murias M, Webb SJ, Greenson J, Dawson G. Resting state cortical connectivity reflected in EEG coherence in individuals with autism. Biol. Psychiatry 2007;62:270-273. [PubMed: 17336944]

Pelphrey KA, Sasson NJ, Reznick JS, Paul G, Goldman BD, Piven J. Visual scanning of faces in autism. J. Autism Dev. Disord 2002;32:249-261. [PubMed: 12199131]

O'Connor K, Hamm JP, Kirk IJ. Neurophysiological responses to face, facial regions and objects in adults with Asperger's syndrome: An ERP investigation. Int. J. Psychophysiology 2007;63:283-293.

Paller KA, Gonsalves B, Grabowecky M, Bozic VS, Yamada S. Electrophysiological correlates of recollecting faces of known and unknown individuals. Neuroimage 2000;11:98-110. [PubMed: 10679183]

Pfutze EM, Sommer W, Schweinberger SR. Age-related slowing in face and name recognition: evidence from event-related brain potentials. Psychol. Aging 2002;17:140-160. [PubMed: 11931282]

Pierce K, Haist F, Sedaghat F, Courchesne E. The brain response to personally familiar faces in autism: Findings of fusiform activity and beyond. Brain 2004;127:2703-2716. [PubMed: 15319275]

Pierce K, Redcay E. Fusiform function in children with an autism spectrum disorder is a matter of "who". Biol. Psychiatry 2008;64:552-560. [PubMed: 18621359]

Schweinberger SR. Personal name recognition and associative priming in patients with unilateral braindamage. Brain Cogn 1995;29:23-35. [PubMed: 8845121]

Schweinberger SR, Pfuetze EM, Sommer W. Repetition priming and associative priming of face recognition: Evidence from event-related potentials. J.Exp. Psychol. Learn. Mem. Cogn 1995;21:722-736.

Schweinberger SR, Pickering EC, Burton AM, Kaufmann JM. Human brain potential correlates of repetition priming in face and name recognition. Neuropsychologia 2002a;40:2057-2073. [PubMed: 12208003]

Schweinberger SR, Pickering EC, Jentzsch I, Burton AM, Kaufmann JM. Event-related brain potential evidence for a response of inferior temporal cortex to familiar face repetitions. Cogn. Brain Res 2002b;14:398-409.

Smith ME. Neurophysiological manifestations of recollective experience during recognition memory judgments. J. Cogn. Neurosci 1993;5:1-13.

Stahl J, Wiese H, Schweinberger SR. Expertise and own-race bias in face processing: An event-related potential study. Neuroreport 2008;19:583-587. [PubMed: 18388743]

Sterling L, Dawson G, Estes A, Greenson J. Characteristics associated with presence of depressive symptoms in adults with Autism Spectrum Disorder. J. Autism Dev. Disord 2008a;38:1011-1018. [PubMed: 17975722]

Sterling L, Dawson G, Webb S, Murias M, Munson J, Panagiotides H, Aylward E. The role of face familiarity in eye tracking of faces by individuals with autism spectrum disorders. J. Autism Dev. Disord 2008b;38:1666-1675. [PubMed: 18306030]

Tanaka JW, Curran T, Porterfield AL, Collins D. Activation of preexisting and acquired face representations: The N250 event-related potential as an index of face familiarity. J. Cogn. Neurosci 2006;18:1488-1497. [PubMed: 16989550]

Tanaka JW, Pierce LJ. The neural plasticity of other-race face recognition. Cogn. Affect. Behav. Neurosci 2009;9:122-131. [PubMed: 19246333]

Taylor MJ, Smith ML, Iron KS. Event-related potential evidence of sex differences in verbal and nonverbal memory tasks. Neuropsychologia 1990;28:691-705. [PubMed: 2215880]

Teunisse J, de Gelder B. Face processing in adolescents with autistic disorder: The inversion and composite effects. Brain Cogn 2003;52:285-294. [PubMed: 12907173]

Thierry G, Martin CD, Downing P, Pegna AJ. Controlling for interstimulus perceptual variance abolishes N170 face selectivity. Nat. Neurosci 2007;10:505-511. [PubMed: 17334361] 
Trenner MU, Schweinberger SR, Jentzsch I, Sommer W. Face repetition effects in direct and indirect tasks: An event-related brain potentials study. Cogn. Brain Res 2004;21:388-400.

Van Strien JW, Langeslag SJE, Strekalova NJ, Gootjes L, Franken IHA. Valence interacts with the early ERP old/new effect and arousal with the sustained ERP old/new effect for affective pictures. Brain Res 2009;1251:223-235. [PubMed: 19063866]

Webb, SJ. Impairments in social memory in autism? Evidence from behaviour and neuroimaging. In: Boucher, J.; Bowler, DM., editors. Memory in autism. Cambridge, UK: Cambridge University Press; 2008.

Webb SJ, Merkle K, Murias M, Richards T, Aylward E, Dawson G. ERP responses differentiate inverted but not upright face processing in adults with ASD. Soc. Cogn. Affect. Neurosci. in press 10.1093/ scan/nsp002.

Wiese H, Schweinberger SR, Hansen K. The age of the beholder: ERP evidence of an own-age bias in face memory. Neuropsychologia 2008;46:2973-2985. [PubMed: 18602408]

Wilson R, Pascalis O, Blades M. Familiar face recognition in children with autism: The differential use of inner and outer face parts. J. Autism Dev. Disord 2007;37:314-320. [PubMed: 17378032] 


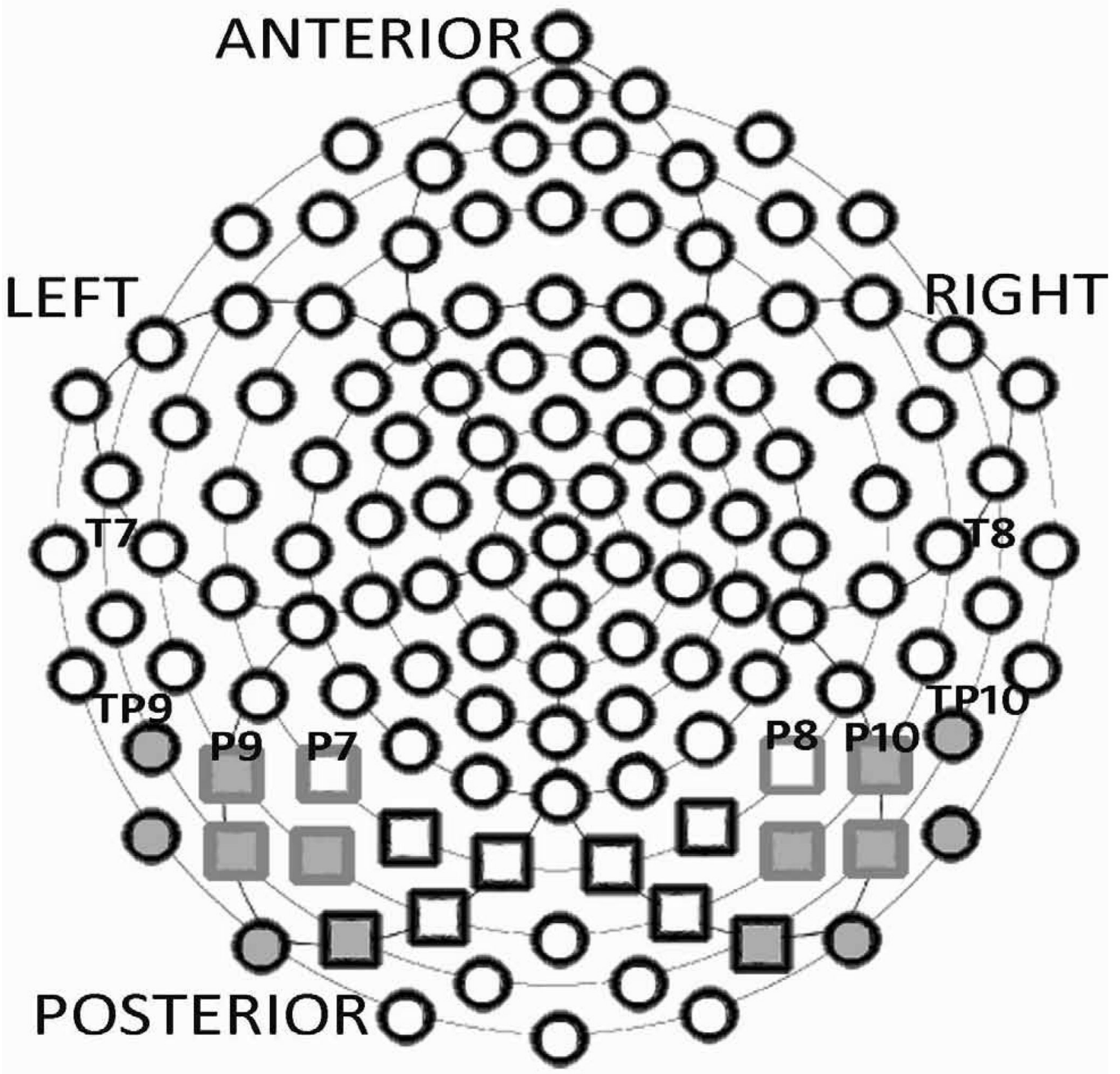

Figure 1.

GSN 128 sensor layout. 10/20 ROI electrodes are labeled by text. Webb ROIs include the medial right and left (black boxes) and lateral right and left (grey boxes) posterior electrodes. Tanaka leads are represented by grey filled posterior electrodes. 


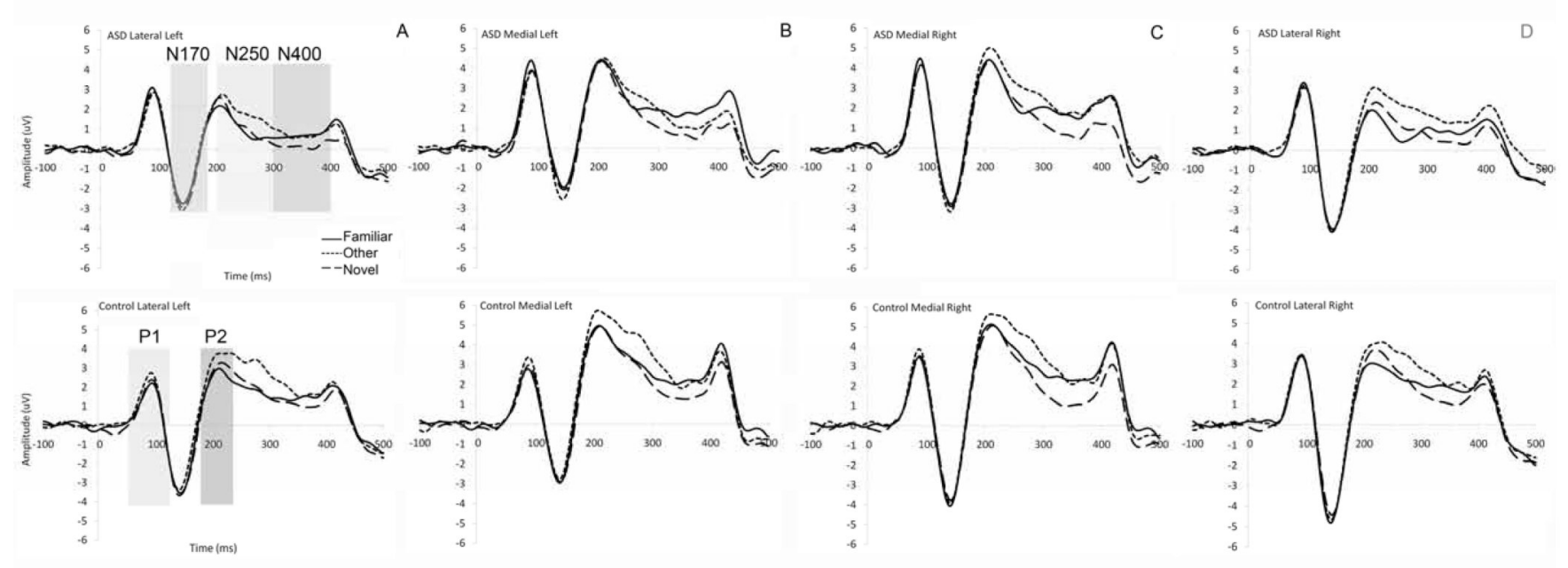

Figure 2.

Grand average waveform across Webb ROIs for ASD (top) and Controls (bottom), (a) mean across left lateral electrode groups with the N250 shaded in light grey and the face-N400 shaded in dark grey; (b) mean across left medial electrode groups; (c) mean across right medial electrode groups; (d) ASD (top) and Controls (bottom), mean across right lateral electrode groups; 


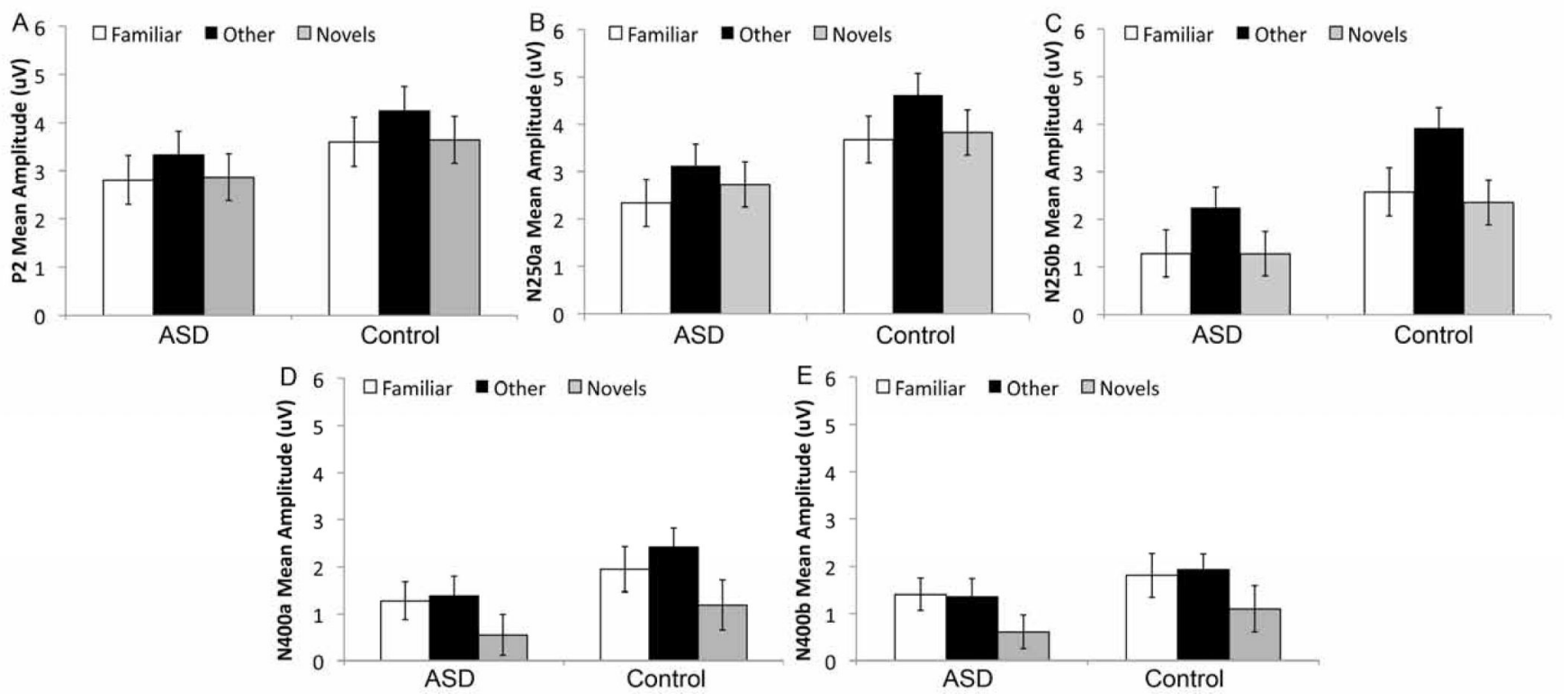

Figure 3.

Mean amplitude of the (a) P2, (b) N250a, (c) N250b, (d) face-N400a, and (e) face-N400b for Familiar, Other (repeated unfamiliar face) and Novels by group collapsed across lead and hemisphere for the Webb ROIs. 


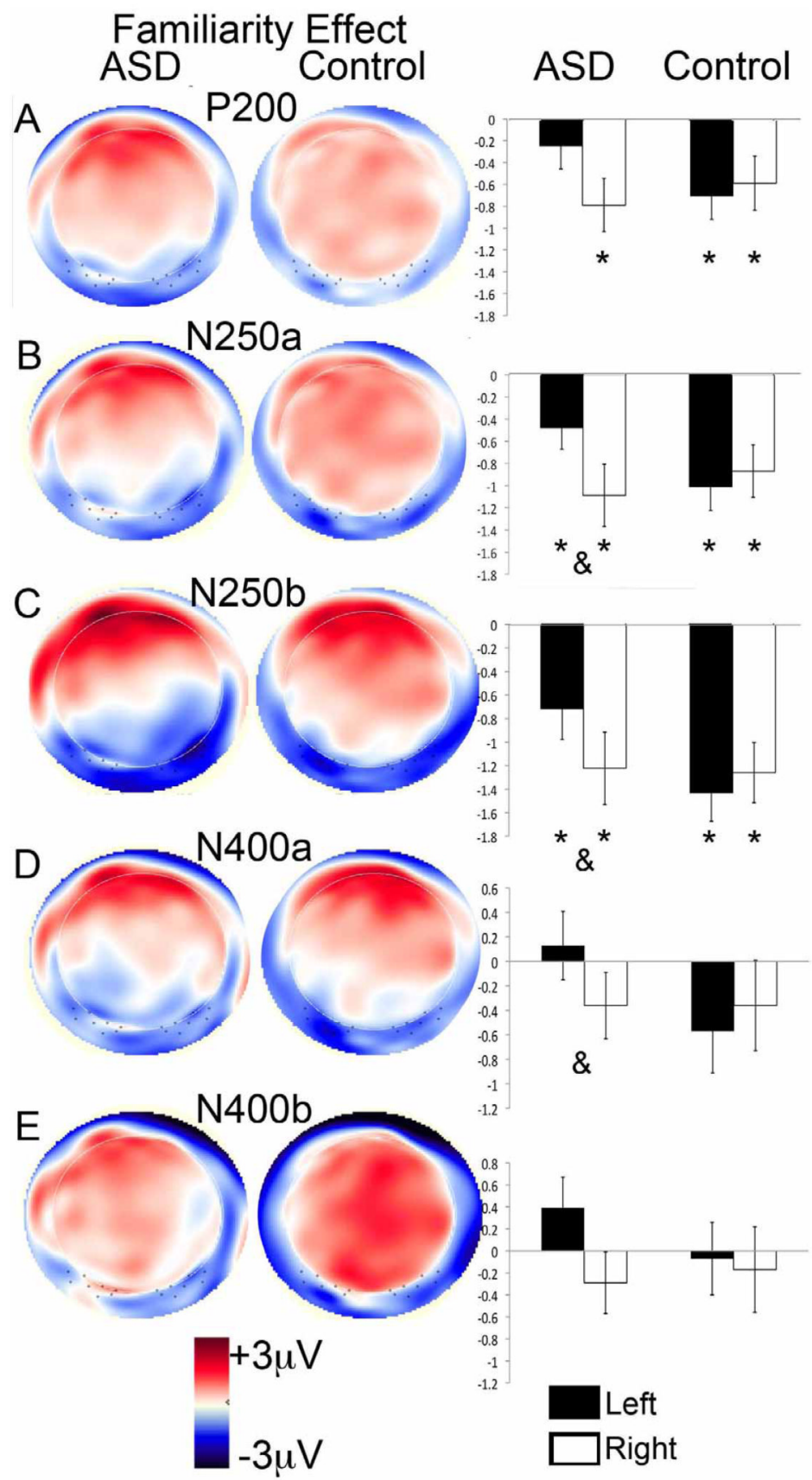

Figure 4.

Topography of the Familiarity effect (Familiar minus Other), showing on the left a topographical amplitude plot for the ERP difference wave (red is positive amplitude and blue is negative amplitude) and on the right the mean amplitude of the difference over left and right Webb ROIs, collapsed across lead for: (a) the P2, (b) N250a, (c) N250b, (d) face-N400a, and (e) face-N400b. An asterix over a bar indicates a significant difference between responses to Familiar and Other; an ampersand $(\&)$ between two bars indicates a significant difference in the Familiarity effect across hemispheres (all $p<0.05$ ). 


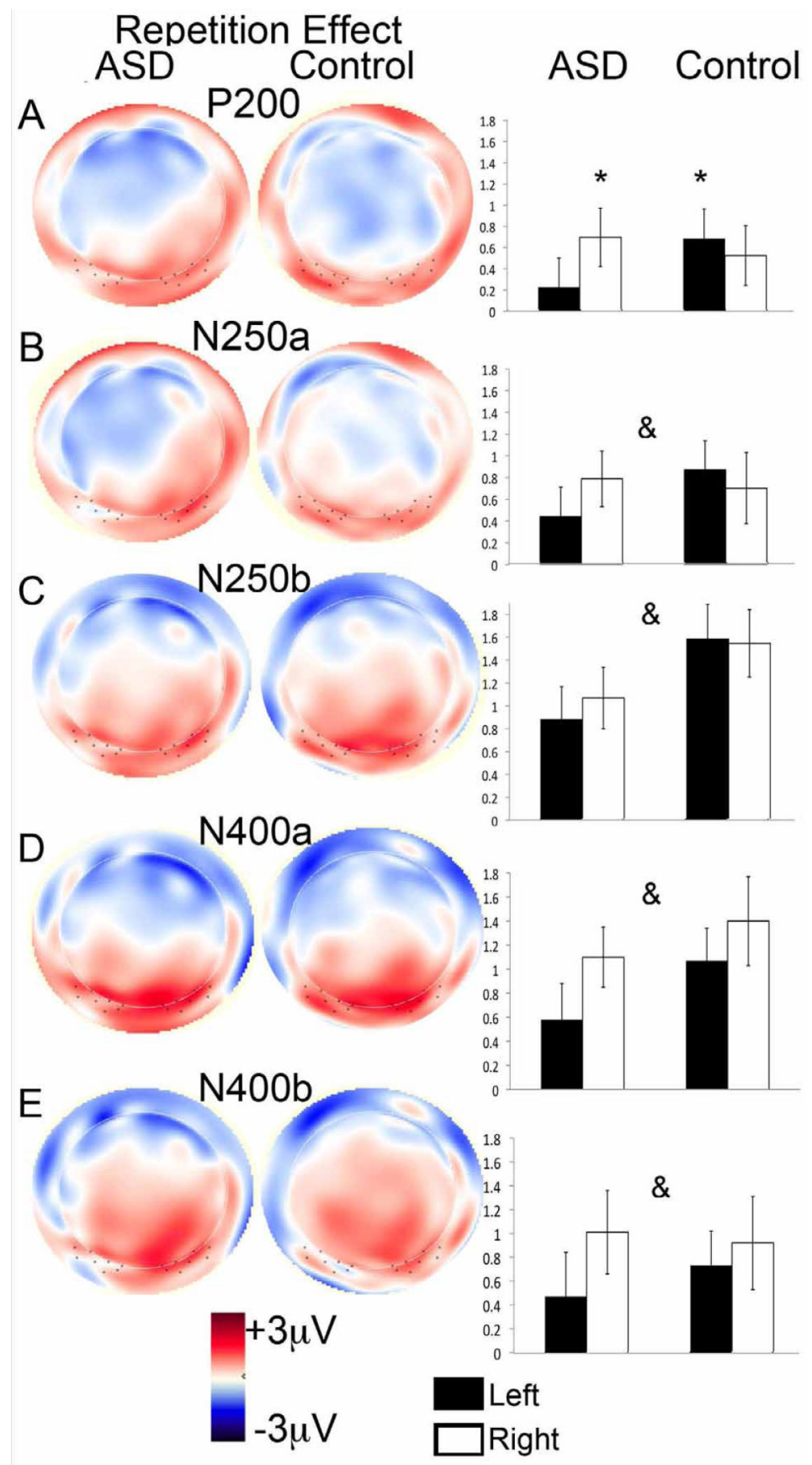

Figure 5.

Topography of the Repetition effect (Other minus Novels), showing on the left a topographical amplitude plot for the ERP difference wave (red is positive amplitude and blue is negative amplitude) and on the right the mean amplitude of the difference over left and right Webb ROIs, collapsed across lead for: (a) the P2, (b) N250a, (c) N250b, (d) face-N400a, and (e) face$\mathrm{N} 400 \mathrm{~b}$. An asterix over an individual bar indicates a significant difference between responses to Other and Novel; an ampersand (\&) indicates a main effect of Repetition across both groups and hemispheres (all $p<0.05$ ). 

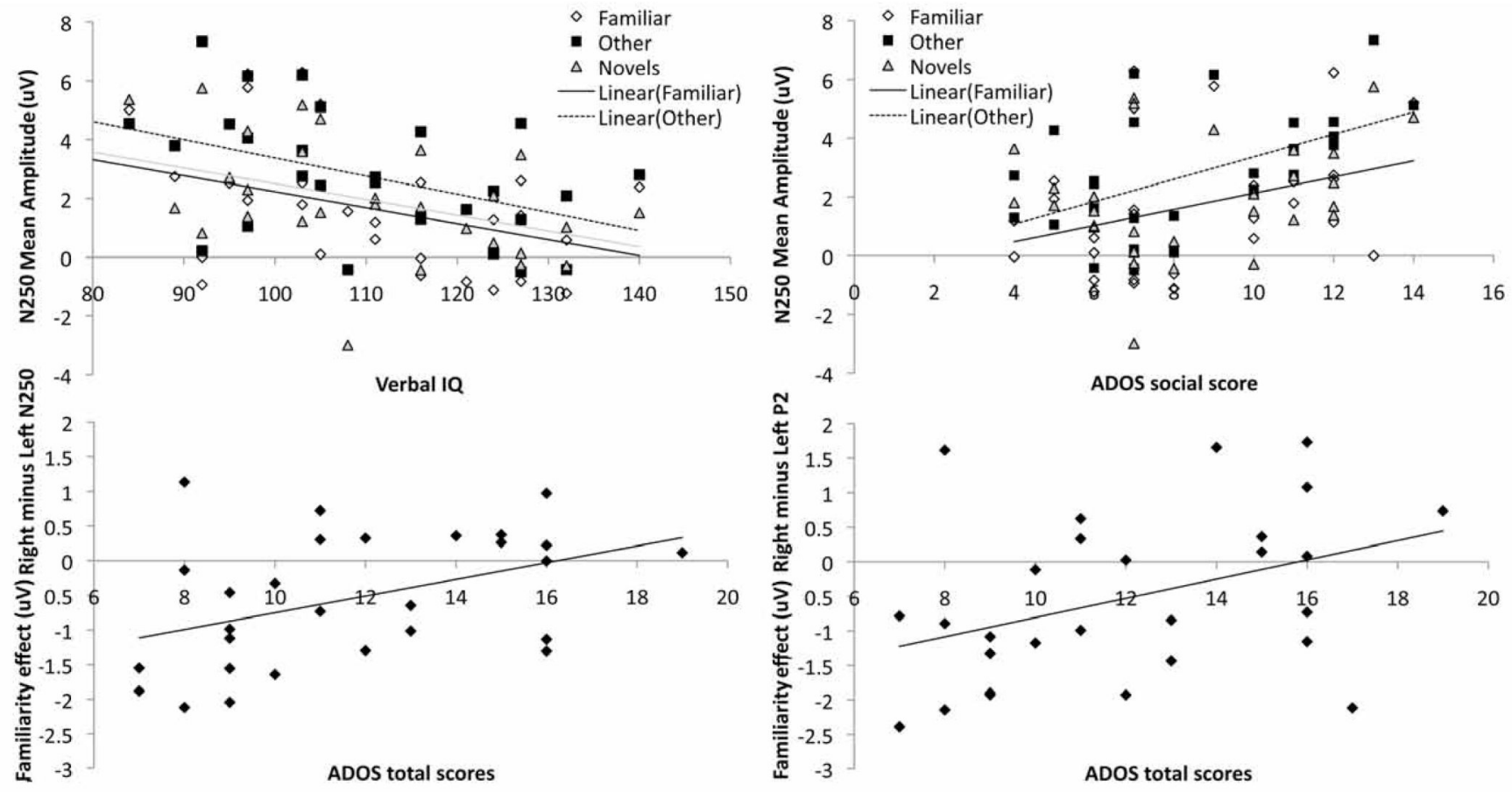

Figure 6.

Relations between behavior and ERP responses to faces over Webb ROIs in the ASD group: (a) More negative-going N250 amplitude correlates with higher verbal IQ for Familiar, Other (repeated unfamiliar face) and Novels, and with (b) lower ADOS total scores (fewer symptoms) for Familiar and Other only; (c) Greater right-lateralization of the N250 Familiarity effect (Familiar minus Other) correlates with lower total ADOS scores, and (d) Greater rightlateralization of the P2 Familiarity effect correlates with lower total ADOS scores. Of note, the N250 was averaged across both $\mathrm{a}$ and $\mathrm{b}$ time windows for the correlation analyses. 


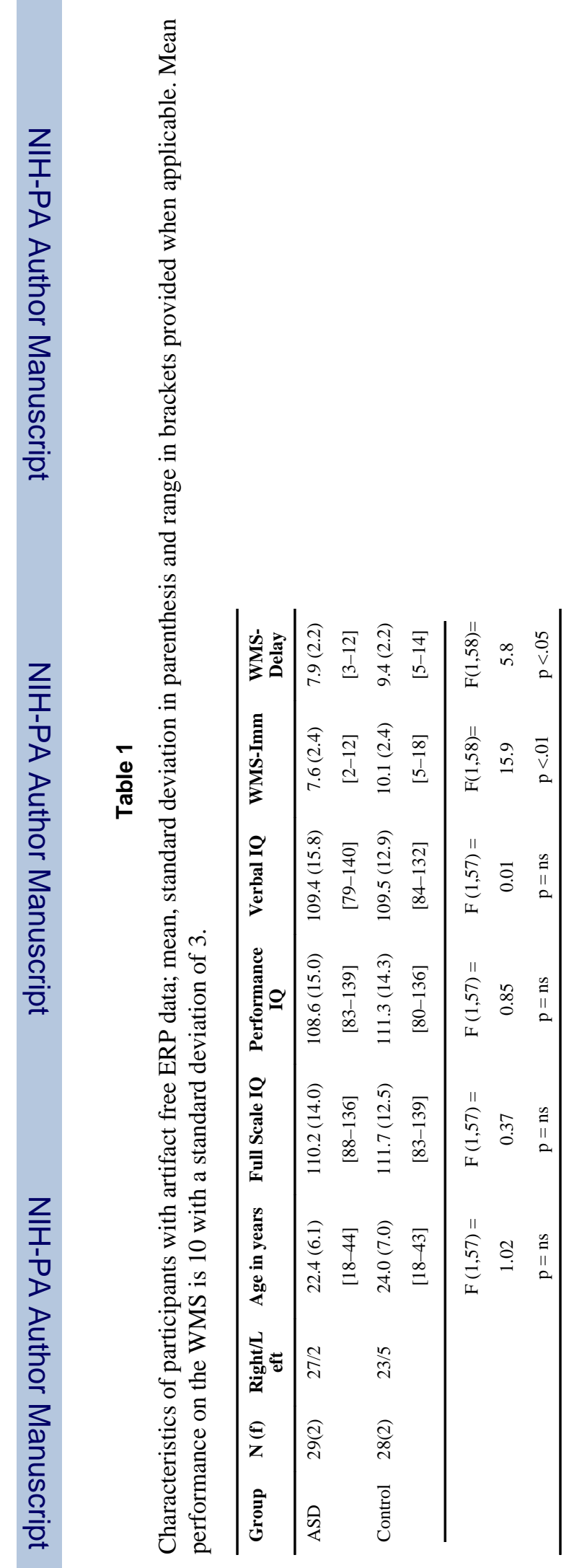

